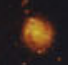

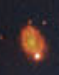

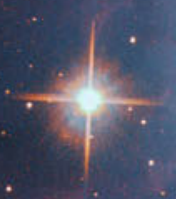

$\vdots$
$\therefore$

\title{
Treasures of the Southern Sky
}

* $\quad$ Robert Gendler : Lars Lindberg Christensen - David Malin
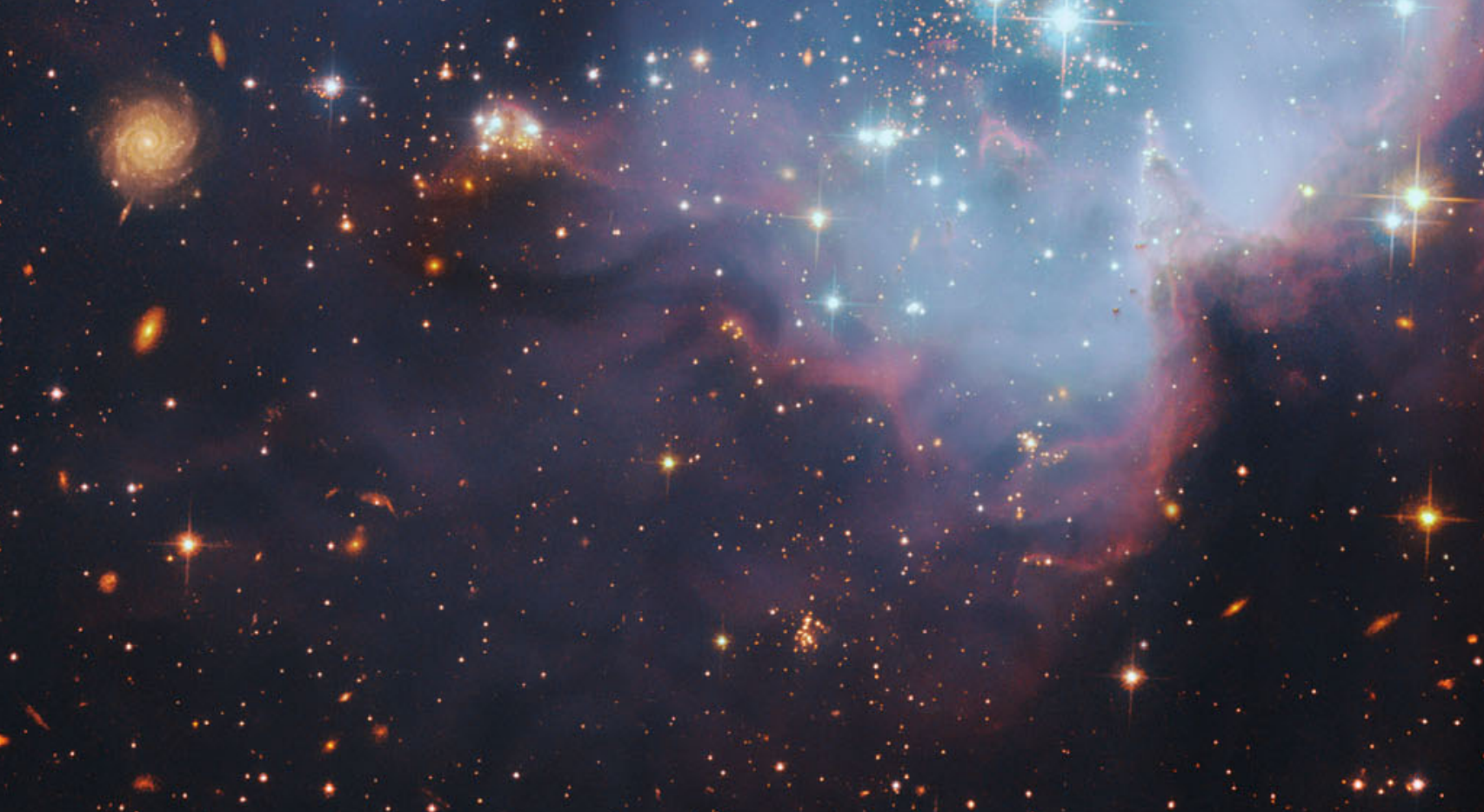


\section{Colophon}

The Authors

Robert Gendler

Lars Lindberg Christensen

David Malin

\section{Design \& Layout}

ESO education and Public Outreach Department/

André Roquette

Library of Congress Control Number: 2011935373

Springer Science + Business Media, LLC, ๑ 2011

All rights reserved. This work may not be translated or copied in whole or in part without the written permission of the publisher (Springer Science+Business Media, LLC, 233 Spring Street, New York, NY 10013, USA), except for brief excerpts in connection with reviews or scholarly analysis. Use in connection with any form of information storage and retrieval, electronic adaptation, computer software, or by similar or dissimilar methodology now known or hereafter developed is forbidden. The use in this publication of trade names, trademarks, service marks, and similar terms, even if they are not identified as such, is not to be taken as an expression of opinion as to whether or not they are subject to proprietary rights.

Printed on acid-free paper.

987654321

springer.com

ISBN: 978-1-4614-0627-3

e-ISBN: 978-1-4614-0628-0

DOI: 10.1007/978-1-4614-0628-0

\section{Cover: The Orion Nebula}

As in the familiar pictures of the Orion Nebula

taken in visible light, this infrared image shows its distinctive bat-like form in the center of the picture, as well as the fascinating surrounding area. At the very heart of this star-forming region lies the compact Trapezium Cluster. This group of very hot, young stars radiates searing ultraviolet light that is clearing the surrounding gas and dust and making it both warm and luminous. Infrared light reveals the warm interstellar material, and also penetrates the dust to show many other young stars that remain unseen in visible light.

\section{Frontispiece: NGC 602}

The star cluster NGC 602 in the Small Magellanic Cloud is surrounded by its natal gas and dust. This image was taken with the NASA/ESA Hubble Space Telescope. Also see p. 192 which shows a different view of NGC 602 with the same dataset. 
To all those who have gazed at the stars and wondered at them 


\section{Table of Contents}

$\begin{array}{lr}\text { Preface } & 6 \\ \text { Introduction } & 8 \\ \text { The Discovery of the Southern Sky } & 10 \\ \text { Star Maps } & 28\end{array}$

\section{The Southern Summer 30}

NGC 1531 and NGC 1532

NGC 1672

LHA 120-N11

NGC 1909

LHA 120-N44

The Large Magellanic Cloud

The Orion Nebula and the Trapezium Cluster

Supernova 1987A

NGC 1999

Tarantula Nebula

The Flame and Horsehead Nebulae

Messier 78

The Monoceros R2 Association

IC 2177 and NGC 2327

NGC 2359

CG 4

NGC 2442

NGC 2440

NGC 2467

The Toby Jug Nebula

Vela Supernova Remnant

NGC 2997

\section{The Southern Fall}

Carina Nebula $\quad 84$

NGC 3293

NGC 3521

NGC 3576 and NGC 3603

NGC 3621

IC $2944 \quad 96$

The Antennae Galaxies 98

The Sombrero Galaxy $\quad 100$

The Coalsack 102

The Jewel Box $\quad 104$

NGC 4945

Centaurus A 108

Omega Centauri $\quad 110$

NGC 5189

Messier 83

NGC 5426 and NGC $5427 \quad 116$ 


\section{The Southern Winter}

IC 4592 and IC 4601

120

The Rho Ophiuchi Nebula

NGC 6164-6165

NGC 6188 and NGC 6193

The Dark Tower

NGC 6302

The Cat's Paw Nebula

Towards the Center of the Milky Way

NGC 6357 and Pismis 24

Messier 7

The Trifid Nebula

The Lagoon Nebula

NGC 6559

NGC 6589 and NGC 6590

Messier 16

Messier 17

NGC 6520 and Barnard 86

Messier 22

Messier 11

NGC 6726

NGC 6744

NGC 6769-NGC 6770-NGC 6771

NGC 6822

\section{The Southern Spring}

The Helix Nebula 168

NGC $7424 \quad 170$

NGC $7793 \quad 172$

NGC 45

NGC $55 \quad 176$

47 Tucanae 178

The Cartwheel Galaxy 180

NGC $247 \quad 182$

NGC $253 \quad 184$

The Small Magellanic Cloud 186

NGC $300 \quad 188$

NGC 346 and LHA 115-N66 190

NGC 602 and LHA 115-N90 192

Messier $77 \quad 194$

NGC $1097 \quad 196$

NGC $1232 \quad 198$

NGC 1313

NGC 1300

NGC 1316

NGC 1365

Books About the Southern Sky 208

Object List and Figure Credits 210

Index 212

About the Authors 218 


\section{Preface}

$\mathrm{B}$ ecause of their diverse backgrounds and experience the authors of this book have arrived at their passion for astronomy from different directions. Nonetheless their love for the subject has converged in a synergistic way within this volume, which celebrates the southern sky in words and with world-class astronomical images. The motivation for assembling this unique visual anthology is to both celebrate the southern skies and to pay homage to the many individuals who have contributed to the advances in southern astronomy. Although the task was formidable we have attempted to accomplish this ambitious objective by searching through many hundreds of images from a variety of professional sources and from renowned amateurs with a southern hemisphere presence.

The professional sources reflect not only the huge growth in ground-based southern facilities in recent years but also the influence of Earth-orbiting satellites that have no hemispheric allegiance. Some amateurs live in the southern hemisphere, while many others are virtual visitors, using remotely operated telescopes from half a world away. We have carefully selected the finest images, covering the full range of objects, some well known and some less familiar, but all equally intriguing. Many of the images have not been widely published before or are being presented in print for the first time. The authors have assembled the text and captions from the most current scientific data available. Just as importantly, the book sheds light on the human story of southern sky exploration by way of an engaging and informative chapter on southern astronomical history.

The images were made from data taken by a wide range of telescopes - from wide-field amateur instruments to professional telescopes with small coverage of the sky - and through a range of different filters - from broadband filters that approximate true color, to narrowband filters that selectively pass light from specific elements. The latter are used to create elaborate images where colors are assigned specifically to map the chemical and physical properties that define that particular object. Regardless of technique, this book brings to print some of the most visually compelling portraits of the night sky seen from the southern hemisphere. 
This book was first conceived as a photographic atlas of iconic astronomical objects of the southern hemisphere. There seemed to be few books dedicated to the visual exploration of the southern sky, so it seemed natural to follow this path. As the concept evolved further it became clear that the story of southern astronomy was more than a scientific one. It was a human adventure as well, characterized by exploration and the search for understanding, and not only in astronomy. It reflects the struggle of many individuals, the gradual advancement of knowledge, and a favorable cooperation among people, institutions, and nations of the southern hemisphere. It became obvious that to do justice to the subject would require a more challenging and extensive treatment. Treasures of the Southern Sky became a celebration of southern astronomy through images and words. The centerpiece would be a visual celebration showcased by the most outstanding and inspirational professional and amateur images of selected southern objects available today. Around this centerpiece the human story would be told through a chapter detailing the history of southern sky exploration. Added to this would be engaging and informative text describing the images, written in everyday terms, but with sufficient detail to satisfy both the serious amateur and the dedicated armchair observer.

This book is arranged by season with objects presented in order of right ascension. We feel that the seasonal approach provides a more fluent experience for the reader and can more effectively serve as a practical guide for observers and photographers who want to conduct their own explorations of the southern sky. The objects featured were carefully selected by the authors for their beauty, visual impact, and scientific interest.

The authors wish to express their gratitude to editor, Maury Solomon of Springer Publishers, New York for believing in and nurturing this project from its conception, and to André Roquette for doing a sterling job on the design. In addition the project would not be possible without the support of the European Southern Observatory.

It is our hope that the pages ahead will do justice to a cherished natural resource, the portal to our larger home in the Universe, which many generations of inhabitants of this small planet have held dear, the night sky.

Robert Gendler, Connecticut, USA, April 2011

Lars Lindberg Christensen, Munich, Germany, April 2011

David Malin, Sydney, Australia, April 2011 


\section{Introduction}

$\mathrm{O}$ November 1, 1520 the Portuguese explorer Ferdinand Magellan and his crew began to navigate the treacherous strait that would later bear Magellan's name. Four weeks later, as they became the first Europeans to reach the Pacific Ocean by an eastern route, they at last had time and leisure to contemplate a new world. This was a world where nature played strange tricks. At these latitudes the Moon appears upside down, Orion is on his head and the height of summer occurs in December. At night, with anchors cast, and freed from more mundane tasks, the crew undoubtedly gazed upward at the blackness of an undisturbed and pristine nightscape. Nowadays we can only imagine the sublime spectacle witnessed by Magellan's men as they gazed at the staggering celestial paradise above them. Well versed in celestial navigation, they were of course familiar with the constellation of the Southern Cross, which had undoubtedly helped guide them throughout their southern oceanic voyage. For millennia the reassuring stars of the Cross served countless ancient and indigenous explorers, who relied on this celestial compass to survive in uncharted seas.

There would have been other wonders of the southern night sky to both tantalize their imagination and fuel their sense of discovery. They may have noticed the collective light of the compact cluster we now know as the Jewel Box. As they gazed north of the mysterious Coalsack, the black patch separating the two brightest stars of the familiar Cross, the men with the best vision may have noticed the small bright patch of light representing the million stars of Omega Centauri or even the faint smudge of light we now call the Carina Nebula. To the west, occupying a sprawling ocean of sky, the vast and luminous star clouds of the southern Milky Way must have offered an imposing vista unspeakable in its beauty and grandeur. Finally, further south, two odd clouds, seemingly detached portions of the Milky Way, must have challenged the familiarity of even the most experienced sailors among them. These companion galaxies of the Milky Way were to become known as the Magellanic Clouds.

It would be centuries before we understood the true nature of these curious and magnificent objects, but even well before the age of modern astronomy these nighttime wonders infused each generation of sky watchers with a rich sense of nature's grandeur and mystery. During the period of Magellan's circumnavigation and for several centuries thereafter, most people lived north of the equator and early northern astronomical observers enthusiastically embraced and charted much of the northern sky, while just beyond their horizon the southern sky remained mostly out of reach. Only those southern objects closest to the celestial equator could be cataloged. Anything further south remained hidden from view, and for a long time the southern sky below a declination of -30 degrees was considered virgin territory.

The main contributors to the astronomical knowledge of the ancient world and the pre-modern era accomplished their work from northern latitudes, and their names have been indelibly stamped into the history books of astronomical exploration. The pioneers and observers from southern latitudes, although highly proficient and accomplished in their own right, were less often the subjects of fame and recognition than their northern counterparts and even today are not quite such familiar names in astronomical history. Contributors to the exploration and charting of the southern skies included observers such as the Abbé de Lacaille, Edmond Halley, James Cook, Charles Green, William Dawes, James Dunlop, Carl Rümker, and John Tebbutt. They and many others advanced southern astronomy and conducted their systematic charting and cataloging of the southern sky from observatories in Australia, New Zealand, and South Africa.

Eventually several renowned northern observers made their way to southern latitudes, mostly to complete work primarily focused on the northern sky. Sir John Herschel, probably the most recognized name in observational astronomy, traveled to the Cape of Good Hope in 1834 and spent four years charting the southern sky. It wasn't until the age of the large professional observatories of the 20th century that objects of far southern declination were intensely studied. In the 1970s David Malin's photographic portraits of southern showpieces taken from the Anglo-Australian Observatory showed once and for all that the southern sky was not only a valuable source of potential astronomical knowledge and discovery, but also of astounding beauty. 


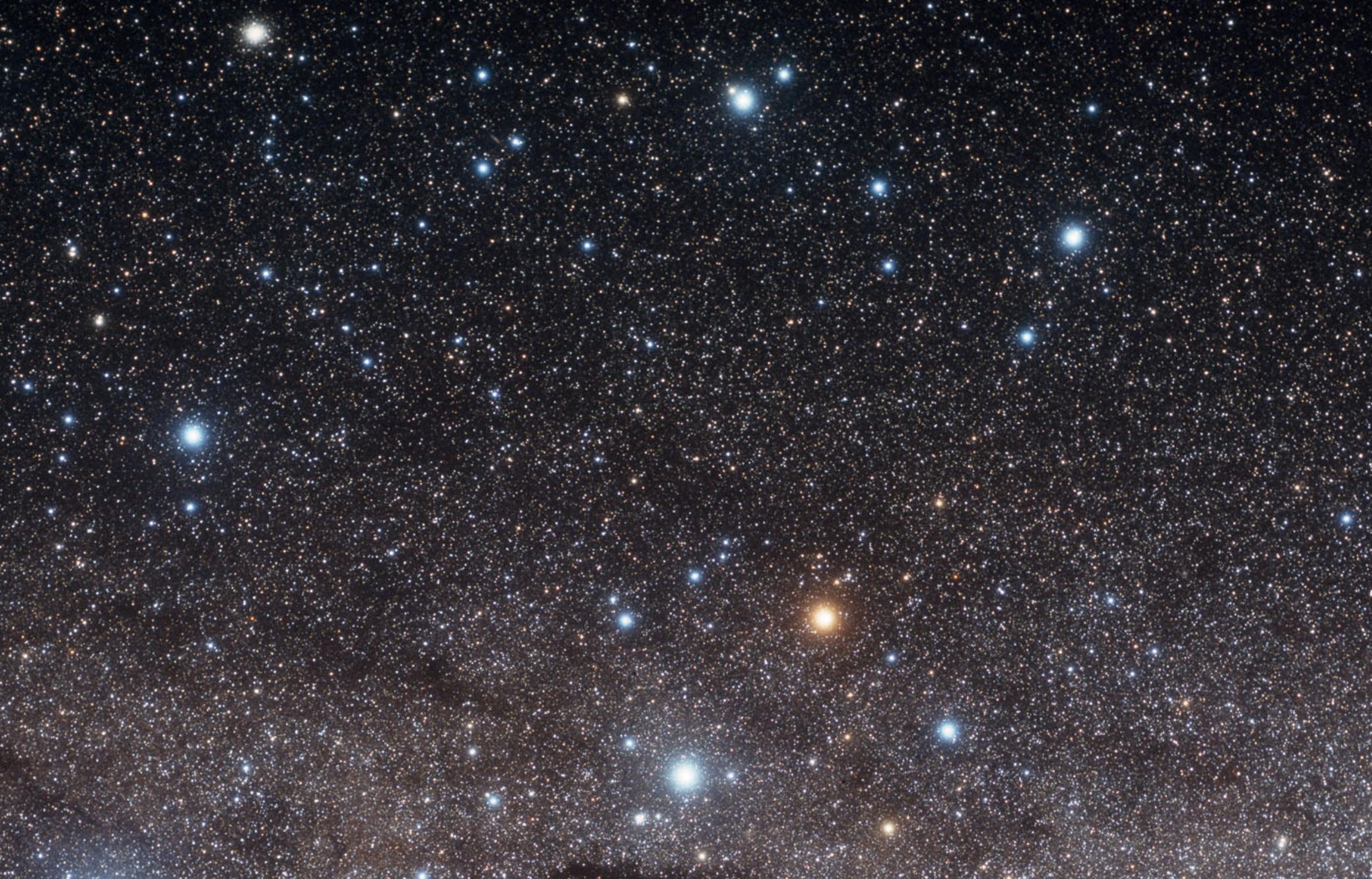

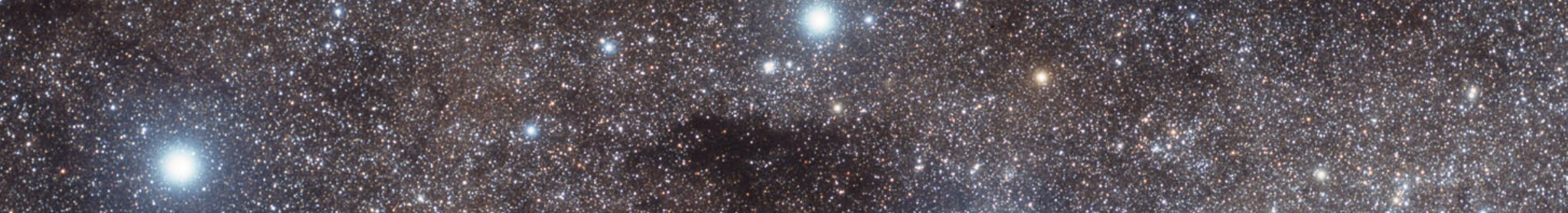

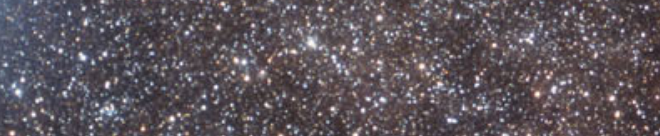

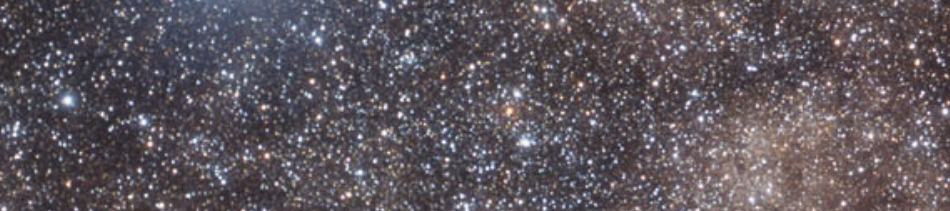

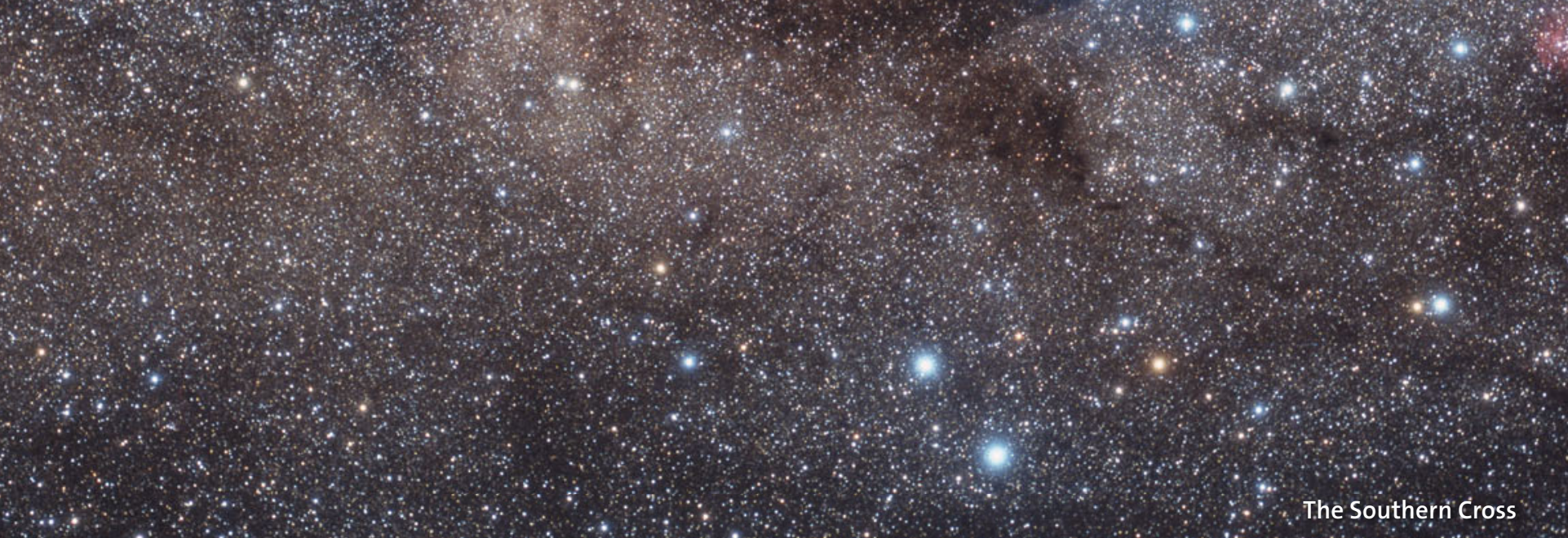

$\therefore$ Crux, the smallest constellation of all contains some of the brightest stars of the southern sky. The kite shaped asterism of the Southern cross appears on many of the flags and national sy mbols of soutthern hemisphere nations, and is visible at some time of the year.from everywhere south of the Tropic of Cancer, and at some time of every night of the year from south of the Tropic of Capricorn See also p 102 


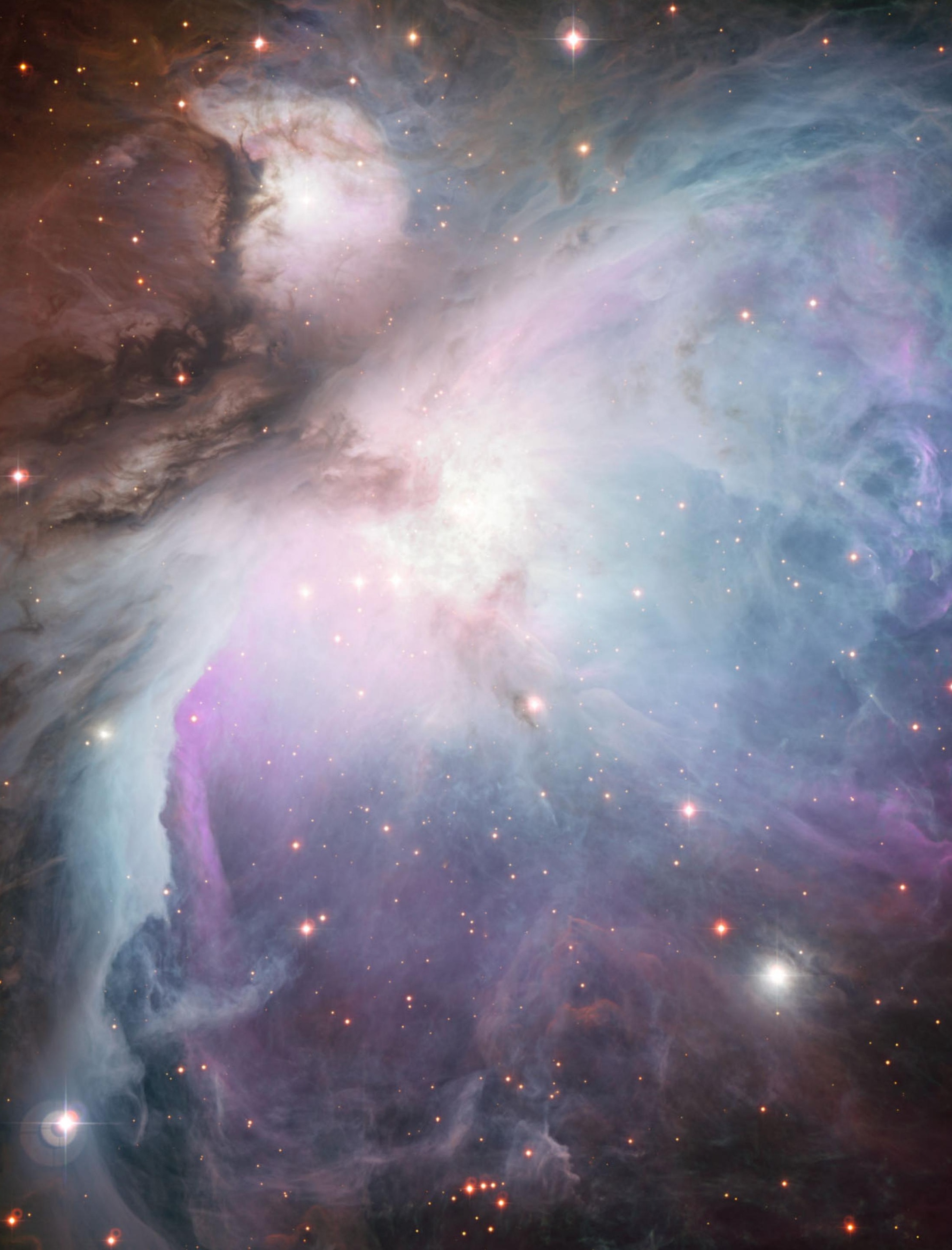




\section{The Discovery of the Southern Sky}

ompared to the northern hemisphere, the southern half of our planet is mostly ocean. What land

there is, is sparsely populated, with few major cities and hardly any heavy industry. Fortunately, the modern air-borne industrial dust pollution that affects most of the northern hemisphere does not cross the equator, and what little pollution that is created in the south is cleansed by the immense oceans. This is one reason why the southern stars are mostly seen through clear air that neither dims nor scatters their splendid light.

However the relative scarcity of land and vast tracts of turbulent ocean also explain why the southern (and western) hemisphere remained largely unknown to Europeans until improved ships and relentless - curiosity, driven by trade and conquest, encouraged intrepid mariners to sail far out of sight of land. They began to sail down the west coast of Africa, south of Cape Bojador, which is 26 degrees north of the equator on the coast of Morocco. There the forbidding seas were long considered to mark the edge of the ancient world, a view that had evolved from familiarity with the safe inland waters of the Mediterranean.

\section{The Orion Nebula}

The magnificent and memorable constellation of Orion the Hunter is bisected by the celestial

equator, and the Orion Nebula itself is just within in the southern hemisphere. It is easily visible to the unaided eye under dark skies and can be seen as a misty patch in the sword handle of Orion from all permanently inhabited parts of the globe. It is described in more detail on p. 44 


\title{
Sailing south
}

These explorations began in earnest in the 15th century, when the names of Christopher Columbus (1451-1506), Ferdinand Magellan (1480-1521), and Vasco da Gama ( 1460-1524) appear in the record. While these sailors would have had a close professional interest in the stars, and Magellan (posthumously) gave his name to the Magellanic Clouds, these are not the most obvious or distinctive celestial features visible from southern latitudes. That honor goes to that rich part of the Milky Way that extends through the southern part of Centaurus and into Crux and Carina and includes the most conspicuous part of Gould's Belt.

The glory of the southern sky, and especially the Southern Cross, first seems to have been mentioned by Dante Alighieri (1265-1321), in his Divine Comedy, written around AD 1300. Although the sight was not visible from northern Italy, Dante probably worked from ancient legends to describe four stars near "the other pole," and the deprivation of those who have never seen them:

\author{
To the right hand I turn'd, and fix'd my mind \\ On the other pole attentive, where I saw \\ Four stars ne'er seen before save by the ken \\ Of our first parents. Heaven of their rays \\ Seem'd joyous. O thou northern site! Bereft \\ Indeed, and widow'd, since of these deprived.
}

(Dante Alighieri: Purgatorio Canto I:1-27)

In describing four stars seen only by "our first parents," Adam and Eve, Dante ignores the existence of the indigenous peoples of the southern hemisphere, probably because he was unaware of them. However, he assigned the four principal virtues - Justice, Prudence, Fortitude, and Temperance - to these stars, and these are all well-known attributes of those who live in the southern hemisphere! The four stars in Crux were also noted by the Italian explorer Amerigo Vespucci (1454-1512) in 1501 and the Portuguese aristocrat Bartolomeu Dias (1457-1500), who was the first to sail round the Cape of Good Hope in 1488. However, the Cross was named by the Florentine Andrea de Corsali (1487-?), who, in a letter written in southern India in 1516, described it (in a later English translation) as “...this crosse is so fayre and bewtiful...". His letter also includes the first drawing of the Southern Cross and the Magellanic Clouds.

The Southern Cross Akira Fujii's classic photograph of the Southern Cross and the dark shape of the Coalsack, silhouetted against the Milky Way. The whole scene is ornamented by the two pointers to the Cross, alpha and beta Centauri (top). White alpha is the nearest bright star and one of very few bright stars with a color (and thus temperature) similar to the Sun. 


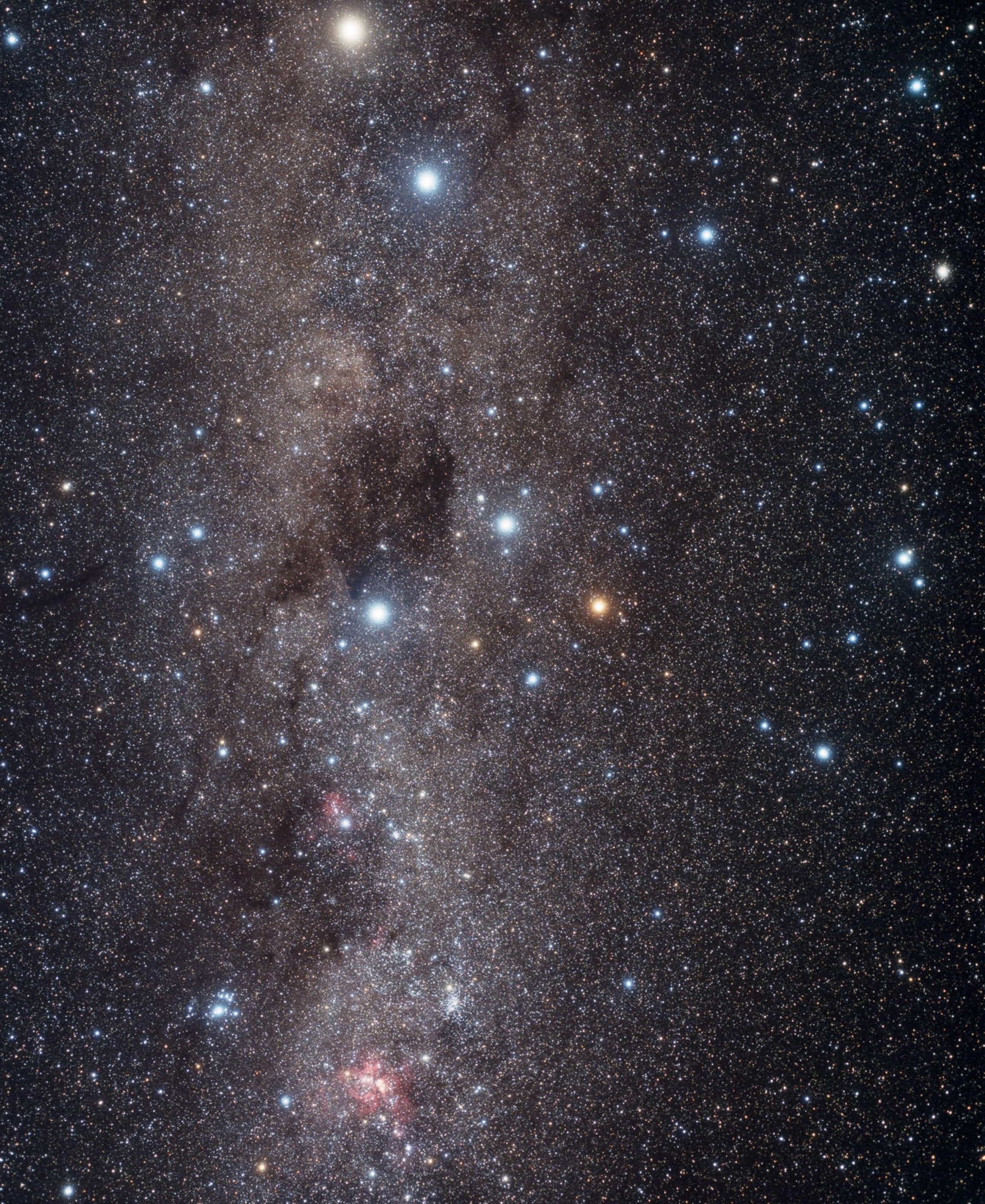




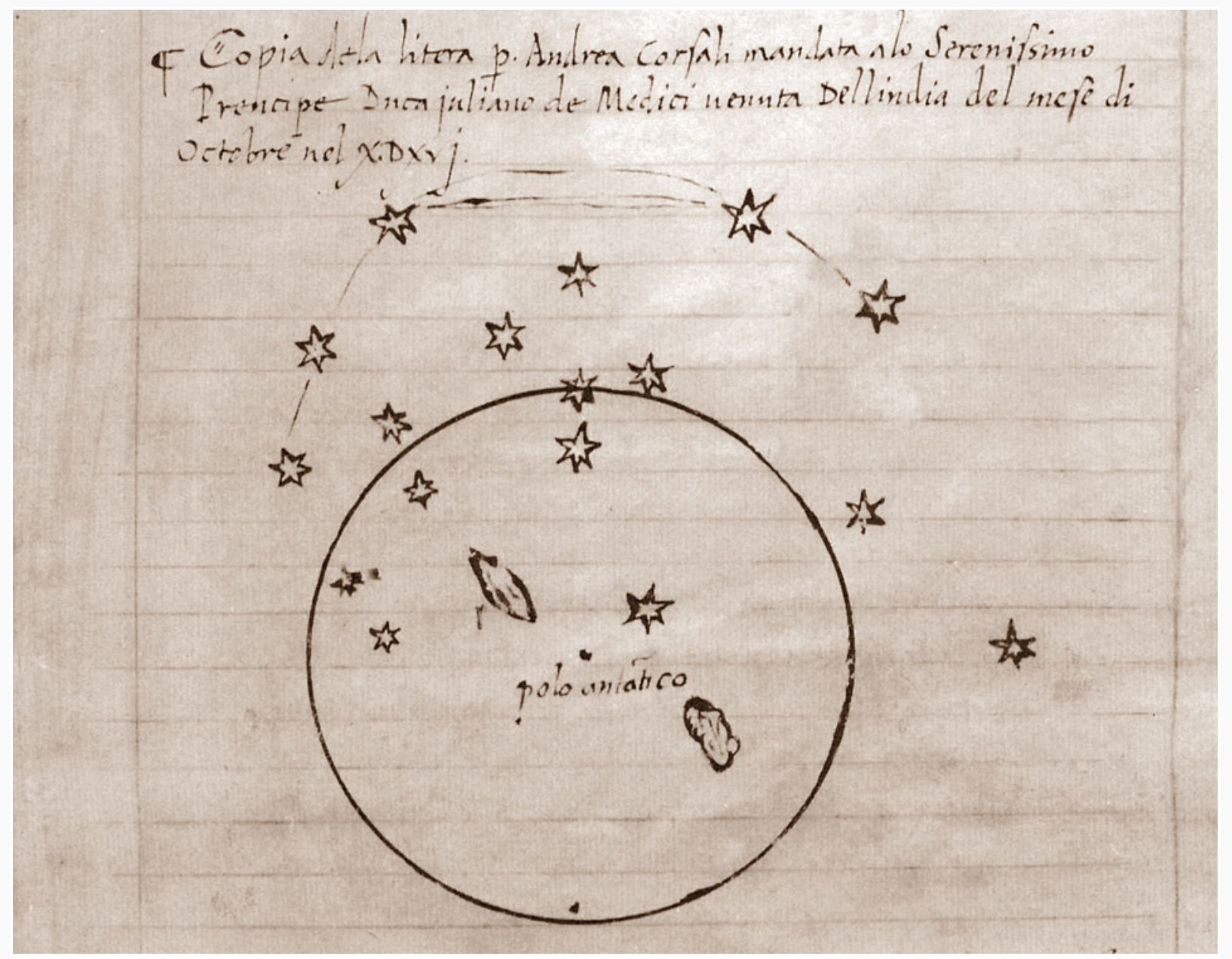

\section{The First Drawing of the Southern Cross}

Corsali's sketch of the Southern Cross, the Magellanic Clouds, and the polo antartico (south celestial pole), drawn in 1516.

The few ancient constellations that both extend substantially below 50 degrees south and contain many bright stars were known to Ptolemy and include Ara, Argo Navis (now split into Carina, Puppis, and Vela), and Centaurus (which included Crux). The extensive part of the sky south of 50 degrees that is mostly devoid of bright stars remained uncharted in ancient times. That changed with the southern voyages of exploration, and significant additions were made by the Dutch navigators Pieter Dirkszoon Keyser (1540-1596) and Frederick de Houtman (1571-1627) on trading expeditions to the spice islands of the East Indies (south and southeast Asia). Their new constellations were Apus, The Bird of Paradise (sometimes Apis, The Bee), Chameleon, Dorado, Grus, Hydrus, Indus, Musca, Pavo, Phoenix, Triangulum Australe, Tucana and Volans. They were defined and named by Johann Bayer (1572-1625) and appear in his famous Uranometria of 1603. However Crux had already been outlined in 1597-98 as the Christian Cross by the Dutch mapmaker Petrus Plancius (1552-1622), who had encouraged Keyser and Houtman to chart the southern skies on their voyages. 


\section{Edmond Halley and the Abbé de Lacaille}

The first recognized astronomer to do any systematic work in the southern hemisphere was Edmond Halley (1656-1742) of comet fame. He went to the remote island of St Helena, 16 degrees south of the equator in the South Atlantic, and was there for 18 months in 1677-78. Though his main motivation was to make a catalog of southern stars to match Flamsteed's northern catalog, he also observed and precisely timed a complete transit of Mercury across the Sun's disk.

This was to have a profound effect on the pursuit of astronomy for 200 years, in both hemispheres. Later, Halley wrote, "On observing this I immediately concluded, that the sun's parallax might be duly determined by such observations,... though Mercury is to be frequently seen within the sun's disk; he will scarcely be fit for the present purpose." The "present purpose" was measuring the solar parallax, and from it an accurate value for the astronomical unit, the distance to the Sun from Earth. From this distance the scale of the whole Solar System could be derived. But the planet that would be most suitable for transit measurements was Venus, which offered the prospect of achieving greater precision, despite its less frequent transits. The other main outcomes of Halley's first southern sojourn was a catalog of 341 southern hemisphere stars and his discovery of the globular cluster Omega Centauri.

Seventy years elapsed before the next major astronomical explorer ventured south of the equator. This was the Abbé Nicolas de Lacaille (1713-1762). Although he had a Jesuit education, Lacaille (as he is usually known) was mainly interested in mathematics and astronomy, and like Halley he was diligent, persistent and imaginative. He had new ideas for a catalog of the "fixed stars" in the southern hemisphere and was keen to make the first measurement of an arc of the meridian south of the equator. While this sounds like surveying (and was), it had a very strong astronomical flavor, since observations of the stars from two accurately defined, but well separated, points could reveal the true shape of the Earth. This was a French obsession at the time, since the meter was defined as one ten-millionth of the distance from the equator to the pole. But which pole, and along which meridian? And did it matter? It did, since the validity of the metric system depended on its universality - and a precise definition of its most fundamental unit, the meter. It also mattered to Lacaille, because this definition of the meter was partly his idea.

Lacaille arrived in what is now Cape Town in April 1751 and set up a small observatory in the Dutch settlement. As with Halley, one of his priorities was to measure the scale of the Solar System, for which he made detailed observations of Mars, the Moon and the Sun itself. Although he worked intensively on these projects, today it is Lacaille's catalog of the positions of almost 10,000 stars that we recall, and his invention of 14 new southern hemisphere constellations. His stellar observations were made with a telescope of $13 \mathrm{~mm}$ (half-inch) aperture, and all of his considerable body of work in South Africa was accomplished in less than two years. 
A chart with the new constellations was published with his star catalog after his death in 1763 , and they cover a particularly barren area of the southern sky. Among the more interesting groupings are Mensa (for Mons Mensa, Cape Town's Table Mountain) between the Large Magellanic Cloud, the south celestial pole, and Reticulum (originally Reticulum Rhomboidalis), which refers to the ingenious lozenge-shaped cut-out that he used in his telescope to speed the measurement of numerous star positions. Most of the other constellation figures are assembled from undistinguished stars and represent scientific instruments and machines invented in the Age of Enlightenment, of which Lacaille was an important figure.

Lacaille's careful measurements of the Sun, Moon and Mars did little to establish an accurate value for the solar parallax and the precise size and scale of the Solar System remained uncertain. Careful timing of transits of Venus from widely spaced latitudes, as advocated by Halley, was the obvious approach and for the 1761 transit no fewer than 120 observations were planned, some in the southern hemisphere. At the Cape of Good Hope, which was still a Dutch colony, the observers were a pair of British surveyors, Jeremiah Dixon and Charles Mason, who were later to survey and give their names to a line that symbolically divided North from South in the United States. Despite the large number of widely spaced transit watchers, the results from 1761 event were erratic, with Mason and Dixon among the best; great expectations were held for the next transit, due in 1769. After that there would not be another until 1874.

\section{James Cook and James Dunlop}

British hopes for the 1769 transit were largely pinned on a junior naval officer, Captain James Cook (1728-1779), who was instructed by the British Admiralty to sail to the island of Tahiti, newly colonized by the French, about 18 degrees south of the equator in the Pacific Ocean. He traveled with some simple telescopes, a clock and a Greenwich astronomer, arriving in mid-April 1769 after a voyage of eight months. The transit itself was not until early June, but the ship's crew found many diversions in this tropical paradise, many of them little to do with constructing a temporary observatory. As with previous transit observations, the exact timing of the event was difficult and the overall results showed little improvement on earlier efforts. By the time of the next pair of Venus transits, in 1874 and 1882, photography had been invented and many of these persistent observational problems had been overcome.

After the main scientific purpose of this voyage was completed, Cook opened his sealed orders, which instructed him to continue westwards to map Terra Australis Incognita, the unknown southern continent. He first mapped the islands of New Zealand and then Australia's east coast, claiming both for Great Britain. It is interesting to speculate on how different the demographics of the southern hemisphere would have looked today if the Portuguese navigator Magellan had continued west after rounding Cape Horn instead of heading northwest to his death in the Philippines. 
In April 1770 James Cook entered Botany Bay, close to modern Sydney, in search of supplies, finally leaving Australian waters four months later after a near-fatal shipwreck on the Great Barrier Reef. Cook's astronomically oriented expedition had dramatically increased the size of the British Empire and paved the way for the First Fleet to establish the Colony of New South Wales in January 1788. Most of the first European inhabitants of Australia did not arrive voluntarily, but a simple observatory was established on the shores of Sydney Harbour within a few weeks, both to establish local time and place, and to seek a comet, predicted by Edmond Halley. However, no comet appeared, and the observatory quickly fell into disrepair.

It was not until 1822 that another new observatory was established in Australia. This was in Parramatta, close to Sydney; the observatory and its assistants were personally funded by Thomas Makdougall Brisbane (1773-1860), Australia's sixth governor, a Scotsman and avid astronomer. He brought with him a fellow Scot, James Dunlop (1793-1848), as a general handyman, and German astronomer Carl Rümker (1788-1862). Dunlop quickly made a name for himself, being the first to see the reappearance of Encke's Comet, only the second example of a predicted return of a comet being verified, the first being Comet Halley in 1758. These three disparate characters did not get on; Rümker left Parramatta in 1823 and Brisbane was recalled to Britain in 1825. Dunlop remained, and while he was interested in astronomy, and had made telescopes for Brisbane, his education was rudimentary and he was not a trained astronomer.

Despite his shortcomings, Dunlop was a diligent observer, and by 1826 he had created a well-known catalog of 7385 stars (known as the Brisbane Catalogue), including about 170 double stars. This was enthusiastically presented to the Royal Astronomical Society in 1827 by John Herschel (1792-1871), son of the famous discoverer of Uranus. Dunlop later expanded his double star catalog and made a catalog of nebulae and clusters using his 9-inch aperture 9-foot reflector. He writes:

"I trust this catalogue of the nebulae will be found an acceptable addition to that knowledge .... respecting that important and hitherto but little known portion of the heavens."

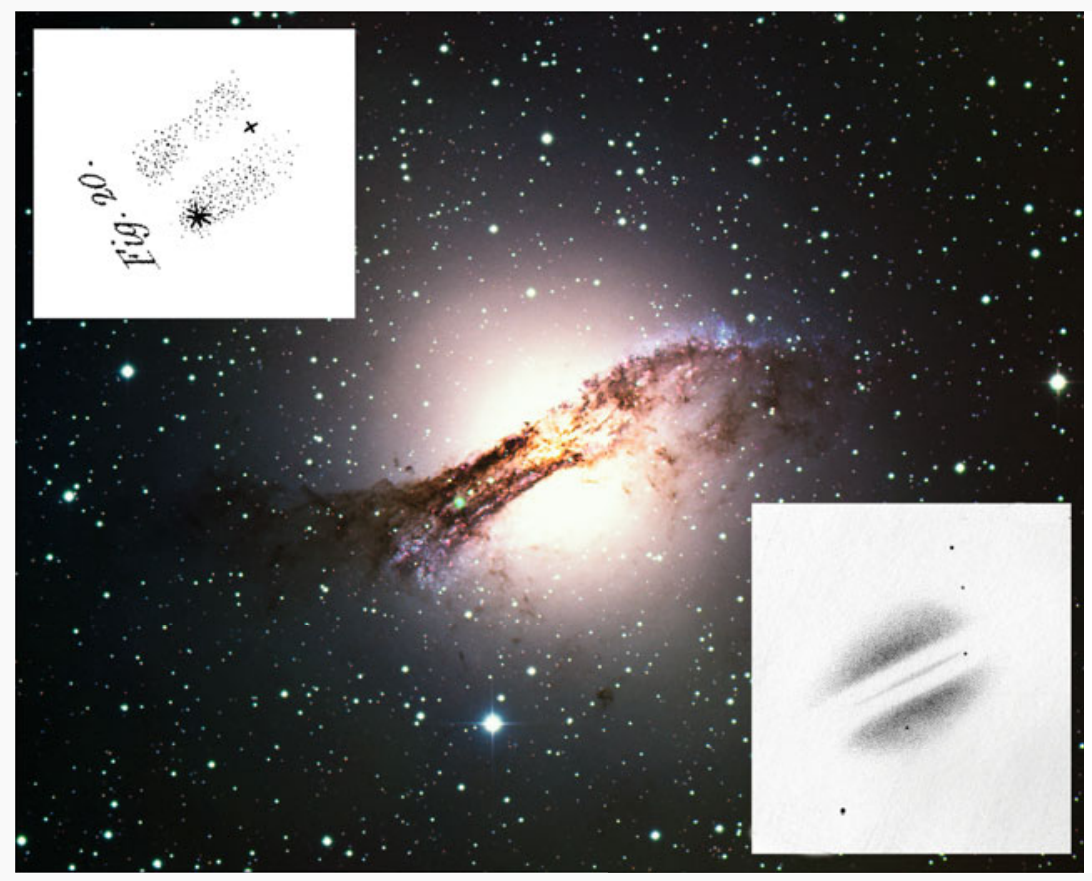

\section{Centaurus A Through History}

AAT color photograph of NGC 5128 (Centaurus A), with Dunlop's discovery drawing (upper left) and Herschel's drawing at lower right. 
His trust was well placed. Among his drawings was number 482, “A very singular double nebula....."This was John Herschel's number 3501, observed several times almost a decade later and described in his Cape Observations (see below) as "A most wonderful object ... The internal edges have a gleaming light like moonlight touching the outline in a transparency" and "two semi-ovals of elliptically formed nebula appearing to be cut asunder..." and elsewhere as "A very problematic object...." The "problematic object" was NGC 5128 and is now better known as Centaurus A. It was one of the first radio galaxies, discovered by Australian radio astronomers in 1948-49. Its discovery opened up a whole new science, radio astronomy, in which Australia is still a leading player.

Dunlop's fame was largely due to Herschel's endorsements, and it would have been more enduring had it not been for Herschel himself, who was the next major figure to spend time under southern skies. Dunlop was eventually made Government Astronomer for New South Wales, in part because there were no other applicants for the job, but lack of support, ill health, and isolation undermined him. Australia has roughly the same area as the contiguous United States, but its total European population in 1826 was about 50,000 and was widely scattered. The observatory at Parramatta slowly fell into disrepair and was demolished in 1847, and Dunlop himself died shortly afterwards.

\section{John Herschel, Gould's Belt, and the Discovery of Photography}

The British Government had established the Royal Observatory at the Cape of Good Hope in 1820, only a few years after they gained control of the colony from the Dutch. It was intended as the southern counterpart to the Royal Greenwich Observatory, but it was not well funded in its early years, and, like Australia, South Africa was not seen by aspiring astronomers as an attractive post.

The reluctant third director, Thomas Henderson (1798-1844) was thought well suited to the post because he was unmarried and thus unencumbered by the extra expense and inconvenience of a family. On his arrival in 1831 he described the observatory as located in an unpromising, dismal swamp. Reluctant or not, within a year he had measured the parallax of, and thus the distance to, Alpha Centauri, the nearest bright star. Sadly he doubted his result and did not publish, and was distraught to hear in 1838 that Friedrich Wilhelm Bessel (1784-1846) had published the first measurement of the distance to a star (61 Cygni). Henderson did not enjoy the climate or the deprivations of South Africa, and his health failed. He returned to Scotland in 1833 and only published his measurement of the distance of Alpha Centauri after Bessel's result had appeared.

By 1834 the observatory was expecting its fourth director, Thomas Maclear (1794-1879), and he was joined shortly afterwards by his 16-year-old assistant, the talented and eccentric Charles Piazzi Smyth (1819-1900), who a decade later became Astronomer Royal for Scotland. Smyth's enduring claim to astronomical fame is his demonstration that high mountains were the best places for astronomical observatories. He was also a pioneer photographer who took some of the earliest photographs in South Africa, and was the first to publish a book of stereoscopic photographs. 
These interesting characters arrived in Cape Town almost simultaneously with the independently wealthy and independentminded John Herschel (1792-1871), son of the famous William. Although he and Maclear were close, Herschel set up his own observatory, determined to extend his father's detailed survey of the northern sky (which he had repeated) into the south, using an 18-inch speculum reflector similar to the one that his father had constructed. John Herschel may be unique in having surveyed and cataloged both hemispheres in detail, by eye, using a powerful telescope.

Naturally, Herschel had arrived familiar with everything that had been published on southern hemisphere astronomy, but despite his previous enthusiasm he became very critical of Dunlop's work, especially his astrometric positions and most particularly the right ascensions of Dunlop's double star discoveries. Herschel could not find many of them; he was not a vindictive man, and he was right (and righteous) about the errors. While many errors could be traced to the faults in Dunlop's telescope, a few of the listed objects appear to be the result of Dunlop's imagination.

The fruits of Herschel's epic observing habits are in his famous book, Results of Astronomical Observations made during the years 1834, 5, 6, 7, 8, at the Cape of Good Hope; Being the completion of a telescopic survey of the whole surface of the visible heavens, commenced in 1825. The title reflects Herschel's prose style, never using one word where a dozen would do. This wonderful catalog and the graphic descriptions of non-stellar objects and double stars is better known as Herschel's Cape Observations and was published in 1847. It is the source of most of the southern objects that appear in the NGC and includes many interesting and beautiful drawings of iconic southern hemisphere sights, including the Magellanic Clouds and the Carina Nebula.

Like his father before him, Herschel was an astute observer, and not only with the telescope. In his Cape Observations he describes a broad band of bright stars inclined at about 20 degrees to the Milky Way and including the brilliant constellation stars of Taurus, Orion, Canis Major, Puppis, Vela, Carina, Crux, Centaurus, and Scorpius, among others. This broad band is most obvious from the southern hemisphere and is one reason why the southern sky seems much richer than the northern, even to the casual onlooker.

Not much was made of this until it was rediscovered by Benjamin A. Gould (1824-1896). Now known as Gould's Belt, this was an important discovery, reflecting the local stellar structure of the Milky Way, and was published by Gould in 1879 while he was director of the Argentine National Observatory (now the Cordoba Observatory) that he founded in 1868, and from where, in 1884, he made the last sighting of the Great Comet photographed by David Gill, who we will meet later. Gould was the founder of The Astronomical Journal, still a leading scientific journal after 160 years of publication, and he was the first American to receive a PhD in astronomy, from Göttingen University in Germany. There he studied under Carl Gauss (1777-1855), who gave his name to the unit cgs of magnetic field strength. Gould also worked with the French physicist and politician Francois Arago (1786-1853) in Paris.

Arago also deserves a mention here because it was he who proposed that Louis Daguerre (1787-1851), the main inventor of photography, should receive a generous lifetime pension from the French government if he made the details of his remarkable process public. Arago was an astronomer as well as a member of the French House of Deputies (lower house) and was briefly prime minister of France. His 1839 description of the potential uses of photography was surprisingly prescient, and included mapping the Moon, charting the positions of the stars, and stellar photometry. 
Since this book is about imaging it is worth emphasizing the link between John Herschel and photography. The essence of photography is fixing the image to make it permanent. In 1820, as a student of chemistry and long before photography appeared, Herschel discovered that a solution of sodium thiosulfate (hypo) would dissolve the normally extremely insoluble, but light-sensitive silver halides (silver chloride, bromide, iodide). Shortly after his return to England from South Africa in 1838, he learned of Daguerre's invention, and within a short time Herschel had produced his own photograph, a glass negative of his father's famous 40-foot telescope, just a few weeks before it was dismantled. Herschel was close to William Henry Fox Talbot (1800-1877), the Englishman who was also busy inventing a silver-based photographic process, and both the daguerreotype and Fox Talbot's negative-positive process were enormously improved by the adoption of a quick and reliable means of fixing the image. It was also Herschel who invented the terms "negative" and "positive" used in a photographic sense, although Herschel himself never took a photograph through a telescope and died in 1871, before the pioneering work of David Gill and Ainslee Common.

\section{Detecting the unseen and mapping the sky}

Born in 1843, into a family of clock and watchmakers, David Gill (1843-1914) became a moderately prosperous Aberdeen businessman when he took over the family firm, but his main interest was in science, and especially astronomy. In 1869 he took a highly acclaimed photograph of the Moon with his 12-inch reflector, and this brought him to the attention of Scotland's professional astronomy community. By 1871 he was the director of the Dun Echt Observatory near Aberdeen and rapidly gaining prominence because of his exceptional observational skills. In 1879 he was appointed as Her Majesty's (i.e., Queen Victoria's) Astronomer at the Royal Observatory at the Cape of Good Hope (i.e., director), which had by then fallen into a dilapidated state. By the time Gill retired in 1906, as Sir David Gill and laden with honors, it had become the premier observatory in the southern hemisphere.

In September 1882 a bright comet suddenly appeared in the southern sky, and brightened rapidly to be easily visible in daylight as it passed close to the Sun. David Gill wrote that "...it resembled very much a star of the 1st magnitude seen by daylight." Gill had the idea of attaching a portrait camera to a telescope mounting and using the telescope itself to guide on the cometary nucleus. The resulting pictures taken on the then-new dry gelatin plates, in November 1882, were the best ever made of a comet and the first guided astronomical photographs.

In that same year Gill received the highest award of the Royal Astronomical Society (RAS), its Gold Medal; not for his photography, but for his precise measurement of the solar parallax from his observations of the planet Mars some years before. These measurements were made from Ascension Island, which is (just) in the southern hemisphere. Gill remained dedicated to this fundamental problem and later measured the solar parallax by observing asteroids, making extremely demanding visual measurements with a precision heliograph. 


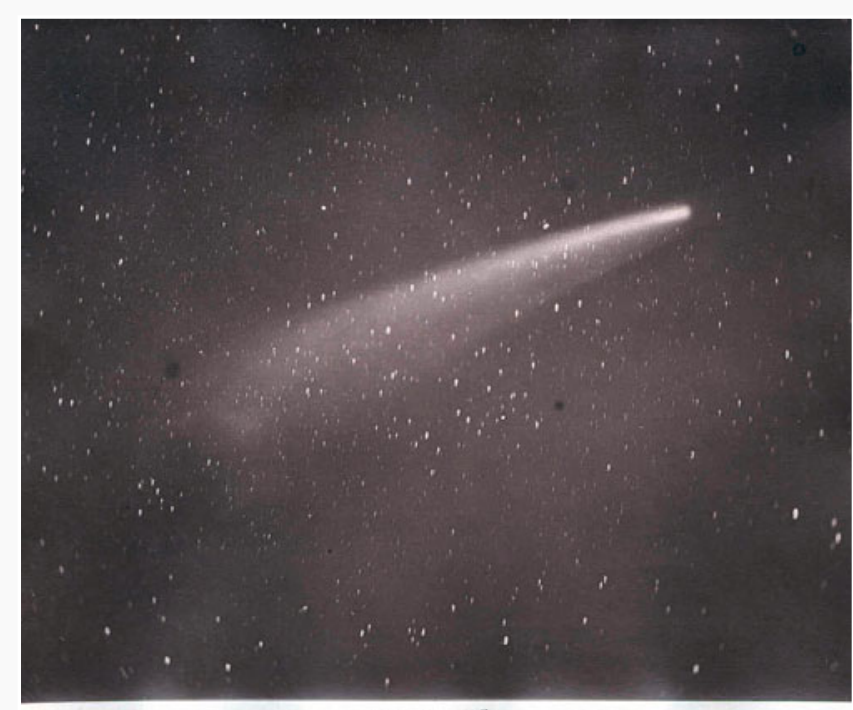

1882 Nov $7^{d}$

\section{The Great Comet of 1882}

Photograph of the Great Comet of 1882, as seen from South

Africa. David Gill's photograph was at that time the best ever made of a comet, and the first guided astronomical photograph.
The award of the RAS Medal was important as it recognized the contributions of southern hemisphere observers, and the following year (1883) it was awarded to Benjamin Gould (of Gould's Belt), who made many southern hemisphere photographs from Argentina. A year later, in 1884, the Medal was awarded to Ainslee Common, for his photograph of the Orion Nebula, which, for the first time, showed stars too faint to be seen by the eye using the same telescope. In J. L. E. Dreyer's History of the Royal Astronomical Society (1820-1920), Dreyer says, "In 1883, Common proposed to Gould, who had photographed about seventy stars clusters at Cordoba, a joint arrangement for photographing the whole heavens..."

Common's Medal is also significant because it recognized the pivotal moment when photography was transformed from a recorder of the visible into a detector of the unseen. In that role photography went on to revolutionize the design of telescopes and indeed the way astronomy was done. It allowed the fledgling science of astrophysics to flourish and opened up all the fields of astronomy we take now for granted - astrometry, spectroscopy, photometry, and of course direct imaging. And finally, David Gill was to receive a second RAS Gold Medal in 1908, specifically for his contributions to southern hemisphere astronomy and as “...a way of recognising Gill's power of inspiring others to take part in advancing [astronomy]..."

While David Gill's 1882 comet photograph was remarkable enough, the thing that most excited him about it was the many faint stars that it revealed. It was clear that long exposure, tracked photographs could be used to map the stars, and this led to his vigorous promotion of two related international projects. One of these was a photographic survey of almost half a million stars in the southern hemisphere done in collaboration with J. C. Kapteyn, which is known as The Cape Photographic Durchmusterung (Survey). This work extended Argelander's earlier Bonner Durchmusterung to the South Celestial Pole. Gill was also a powerful advocate of the Carte du Ciel (CdC), a photographic map of the sky of the kind envisaged by Ainslee Common. This project was agreed on in 1887 at an international meeting of astronomers in Paris, and eventually 20 countries were involved in the preparation of the C $\mathrm{dC}$ and the associated Astrographic Catalogue.

The most prolific contributors to the CdC were the southern hemisphere observatories in Cape Town and Sydney, which measured about a million star positions between them. The Sydney work started in 1892 under the direction of the Government Astronomer, Henry Chamberlain Russell (1836-1907) and was continued intermittently until 1948. The refracting telescopes for the $\mathrm{CdC}$ were standardized, with a focal length of 3.4 meters and an aperture of about 330 millimeters, producing an image on $130 \mathrm{~mm}$ square plates covering about $2 \times 2$ degrees. Such was the demand for these telescopes that orders to the only suppliers, Paul and Prosper Henry in Paris and Howard Grubb in Dublin, were subject to considerable delays. 
Russell had the tube, mount, and an innovative electrical drive system made for his astrograph in Sydney, and it was finished and installed long before the telescope optics arrived. Anxious to do some serious photography, he mounted a portrait camera fitted with a 6-inch lens on the mount and made some long exposure, wide angle photographs of the southern sky. In 1890, the night sky in Sydney was still dark enough to see the Milky Way and the Magellanic Clouds, and these were his targets. He noted that the structure of the Keyhole Nebula around Eta Carinae, carefully sketched by John Herschel 60 years before, had changed, and commented on what he noted was the spiral nature of the Large Magellanic Cloud (LMC). These were important and insightful observations; Eta Carinae is still under close scrutiny and the structure of the LMC remains controversial 120 years later.

Melbourne Observatory also took part in the $\mathrm{CdC}$, and at 38 degrees south, it was the most southerly institution involved. It was assigned the region from -65 degrees to the south celestial pole. Melbourne Observatory was also home of the Great Melbourne Telescope, which, with its 48-inch speculum mirror, was for some years the largest steerable telescope in the world. However, it was designed by a British committee in the 1860s, installed close to sea level in Melbourne, and was difficult to use and maintain. It was also completely unsuitable for photography. Like all the state observatories in Australia, Melbourne was often both under-funded and overburdened with non-astronomical activities such as weights and measures, meteorology and tide tables. All of these state observatories have now closed or are used for popular astronomy education. The Great Melbourne Telescope was transferred to the Mt. Stromlo Observatory in Canberra in 1944 and was extensively damaged in the bush fires of 2003. What remains of it has now been moved back to Melbourne and is being restored by Museum Victoria and the Astronomical Society of Victoria with the aim of returning it in working order to its original building in Melbourne's Botanical Gardens.

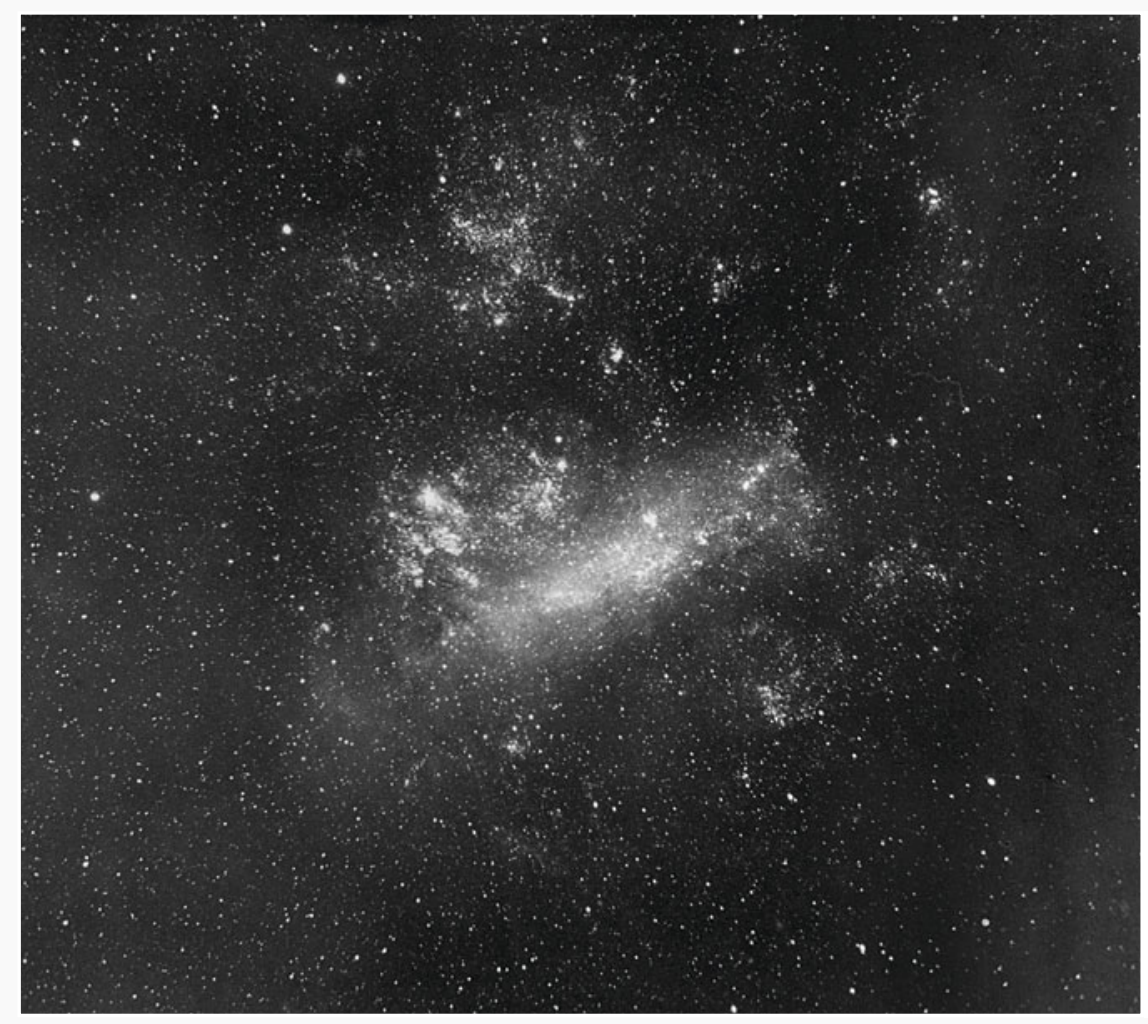

\section{The Large Magellanic Cloud}

The first wide field photograph of the Large Magellanic Cloud, made by H. C. Russell in 1890 using a portrait camera at Sydney Observatory. This image combines three of Russell's photographs. 
The Carte du Ciel was in some ways too ambitious an undertaking for many of the observatories involved and it was never fully completed, mainly because the measurement of star positions from thousands of glass plates was difficult and slow. However, it served to emphasize the importance of photography in astronomy and the international nature of the astronomical enterprise and so strongly influenced the formation of the International Astronomical Union (IAU) in 1919. This is still based at the Observatoire de Paris, where the CdC was instigated, and it is the coordinating body for professional astronomers. It should be mentioned here that while the United States did not take part in the Carte du Ciel project it joined the IAU in 1920.

\section{The urge to look south}

In addition to Benjamin Gould's presence in Argentina, several other South American countries had established national observatories and many of them were involved in the $\mathrm{CdC}$, with varying degrees of success. However, probably the most prominent South American observatory in the early 20th century was at Arequipa in Peru, an institution with a great history of photographic achievement in both hemispheres, the legacy of which is an archive of half a million plates none of them connected with the CdC project. Arequipa was almost entirely as a result of the involvement of the Harvard College Observatory, of which it was an outstation.

Among these are the numerous photographs of the Magellanic Clouds that Henrietta Swan Leavitt (1868-1921) used to establish the period-luminosity relationship of Cepheid variable stars between 1908 and 1912. Cepheids are bright stars and abundant in these nearby galaxies, which are sufficiently far away that the stars in each galaxy could all be assumed to be at the same distance from Earth. From Leavitt's work came the first solid step in the extragalactic distance scale, a marvelous extension of the solar and stellar parallax endeavors that had taxed generations of astronomers who had labored in the southern hemisphere. Sadly, it is thought that Henrietta Leavitt never saw the Magellanic Clouds for herself, but knew them intimately from the plates returned from Peru.

Many of these plates were from the 24-inch Bruce Astrograph, an F/5.6 photographic refractor made by Alvan Clark and Sons, which was later moved from Peru to Bloemfontein in South Africa, where it was used by Harlow Shapley for a survey of southern galaxies. In its day this aperture and focal ratio was considered remarkable, but in 1950 the Bruce telescope was replaced by a 91-cm Baker Schmidt telescope.

The design of the telescopes that bear his name was the result of the genius of Bernhard Schmidt (1879-1935), an optician of Estonian birth, who invented the Schmidt camera in 1928-29. A conceptually simple design with a spherical primary mirror and aspheric corrector plate, the Schmidt camera was the first wide-field, fast focal ratio telescope to be used in astronomy. However, the focal surface is curved and is inside the telescope, inaccessible to a human observer (hence the common name, Schmidt camera). The focal surface could be used with photographic plates if they were thin enough to conform to the curvature. And the image quality was superb over a very wide field, and completely free from the aberrations of refractors. 


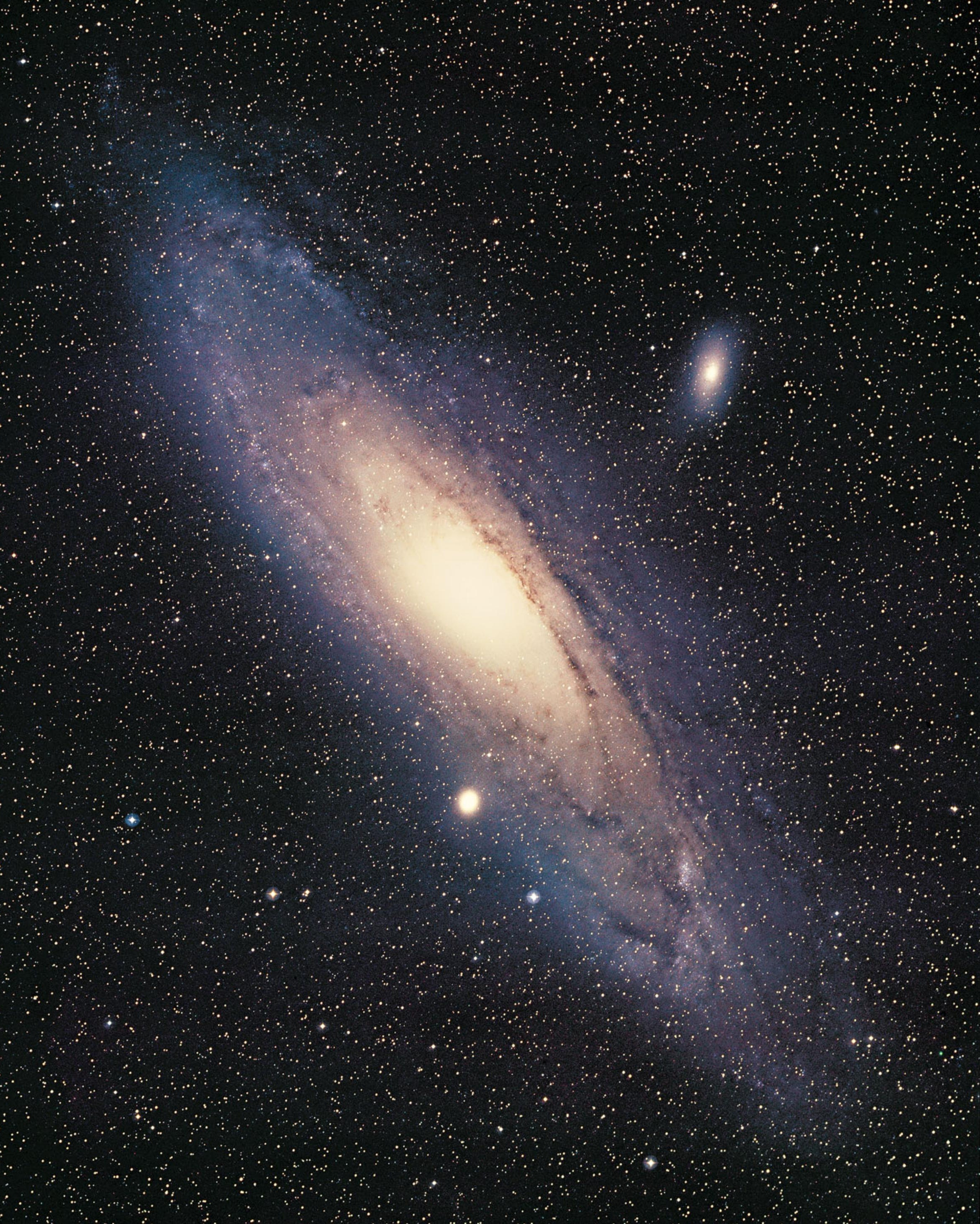


Ever larger Schmidt-type telescopes were built, culminating in the 48-inch (1.2 m) Palomar Schmidt, commissioned in 1948. This is now known as the Oschin Schmidt, and its basic specification is still remarkable. It has a focal length of about 3 meters, works at a focal ratio of F/2.5 and recorded a 6 × 6 degree patch of sky on $356 \mathrm{~mm}$ (14-inch) square glass plates, with a plate scale of about 60 arcseconds per millimeter. Between 1948 and 1958 it was used to make a photographic survey of all of the sky reasonably accessible from Palomar in two colors, red and blue, down to a declination of-33 degrees. This was extended even further south, to -45 degrees on the initiative of John Whiteoak, an Australian radio astronomer, but only in one color, red.

Pushing a northern telescope into its declination limits was an indication of the urgent need for substantial telescopes based in the southern hemisphere, which we will come to shortly. However, among the Palomar Schmidt's many accomplishments we should mention here were some of the first color photographs of the night sky. These were taken by Bill Miller (1910-1981), a photographic scientist at what was then Mt Wilson and Palomar Observatories, using Super Anscochrome transparency film, with a then-astonishing snapshot speed roughly equivalent to ISO 100 . This fell to about ISO 7 during a long exposure.

Although rarely mentioned today, Miller's achievement was considerable, and he put a good deal of effort into understanding and correcting the notoriously unpredictable color balance issues that affected long exposures on color film. It was clear to Miller and others at this time that the special Kodak photographic emulsions that had been used for the first Palomar Sky Survey did not make the best use of the finely detailed images and fast focal ratio of Schmidt telescopes. These emulsions had been designed in the 1930s under the direction of C. E. Kenneth Mees (1882-1960), the founder of the Kodak Research Laboratories. They were the most sensitive photographic emulsion then known and were specially sensitized for long exposures. However, they were also grainy and had poor resolution, but this was not a serious problem with long focal length telescopes and their generous plate scales.

In the late 1960s Miller had been involved in testing a new type of astronomical emulsion from Eastman Kodak. It had fine grain, high contrast and excellent resolution, ideally suited to the new generation of 4-meter telescopes being planned for the 1970s - and for Schmidt telescopes.

Three of these new telescopes were intended for the southern hemisphere. The Cerro Tololo 4-m Blanco Telescope (whose twin is at Kitt Peak National Observatory in Arizona) and the European Southern Observatory (ESO) 3.6-meter at the La Silla Observatory were both built in Chile, while the Anglo-Australian Telescope (AAT) was built at Siding Spring in Australia. ESO would also have a 1-meter Schmidt Telescope and a 1.2-meter Schmidt, based on the Palomar Schmidt design, and would be constructed close to the AAT. All these telescopes were commissioned in the early to mid-1970s, and at last large, modern telescopes had access to the southern skies, 300 years after Halley prepared the first southern star catalog on St. Helena. All of these instruments have been highly successful and have been followed by even larger and more successful instruments, such as the four 8-meter telescopes of ESO's Very Large Telescope, Gemini South, in Chile, and the Southern

\section{Miller's Important Color Photo of Messier 31}

One of the first color astronomical photographs, a 120-minute exposure of Messier 31 made by Bill Miller with the Palomar (now Oschin) Schmidt telescope in 1958. It was taken on 4 x 5 inch film and remastered digitally by David Malin in the 1990 s. 
African Large Telescope in South Africa. Since 2007 ESO's telescopes in Chile have each year collectively provided data for more scientific papers than any other observatory on the planet, or above it - a testament to the extremely clear skies of the southern hemisphere. For the future, the next generation of "extremely large" optical telescopes is now being planned. Two of three will be constructed in Chile in the south, and one in the north in Hawaii. The largest of these, the 40-meter European Extremely Large Telescope (E-ELT), will be built on a mountaintop adjacent to the Very Large Telescope in Chile's Atacama Desert.

Significantly, no new large optical telescopes are planned for Australia, mainly because Australia's highest mountains are too far south to offer clear weather - and not high enough, as Piazzi Smyth would have known. New Zealand has much higher mountains, but is even further south, buffeted by the wild winds and storms of the Roaring Forties. Australia's astronomical strength is today in radio astronomy, which benefits from a long tradition and the enduring success of the Parkes Radio Telescope, completed in 1961. Australia has a small population, most of which lives on the coast. The interior is largely empty - and radio-quiet - and this is perhaps the advantage that Australia's astronomical future will be based on. The Square Kilometer Array (SKA), a radio telescope with a collecting area of a million square meters, is an enormous international project to build a vast, innovative multi-frequency, ultra-sensitive radio telescope. It is planned for construction between 2016 and 2023 and will look back to the dawn of time itself. Its final location is not yet decided, but it will be in the southern hemisphere, either in Australia or South Africa.

To end this celebration of southern hemisphere advances in sky observing, we should remember that astronomy is a completely international science, and the fact that astronomy was late in establishing itself in this hemisphere is simply an accident of history and geography and the limitations of 15th-century ships. The southern advantages of clear air and dark skies are still real and very important, as witnessed by the large investment in ground-based telescopes here in recent years and in the plans for the enormous E-ELT and Giant Magellan Telescope in Chile. However, much astronomy now depends on data from the more than 100 telescopes that have been launched into Earth orbit, such as the Hubble Space Telescope, and scores of orbiting telescopes and detectors that can observe the whole sky at wavelengths from gamma rays to microwaves and beyond. Eventually, Hubble's big sister in the infrared, the James Webb Space Telescope, will be parked (literally) a million miles away from our planet, in an orbit around the Sun. By then, hemispheric chauvinism will be a very distant memory.

The European Extremely Large Telescope

The European Extremely Large Telescope is planned for construction on Cerro Armazones in Chile and will have a 40-meter diameter segmented mirror - the largest of a new generation of Extremely Large

Telescopes. The telescope's "eye" will be almost half the length of a football field in diameter and will gather 15 times more light than the largest optical telescopes operating today.

The Square Kilometer Array

A conceptual sketch of the Square Kilometer Array layout. About 150 stations, about half the SKA area

- will be distributed across continental distances ( 3000 km), either in Australia or South Africa. 


\section{The Southern Sky}

This image on the right shows a 180-degree view of the entire southern hemisphere as it would look to a spectator at the South Pole. From this vantage point, the general components of the Milky Way come clearly into view, including its disk, marbled with both dark and glowing nebulae, and which harbors bright, young stars as well as our galaxy's central bulge (right) and its satellite galaxies, the Large and Small Magellanic Clouds (middle). 


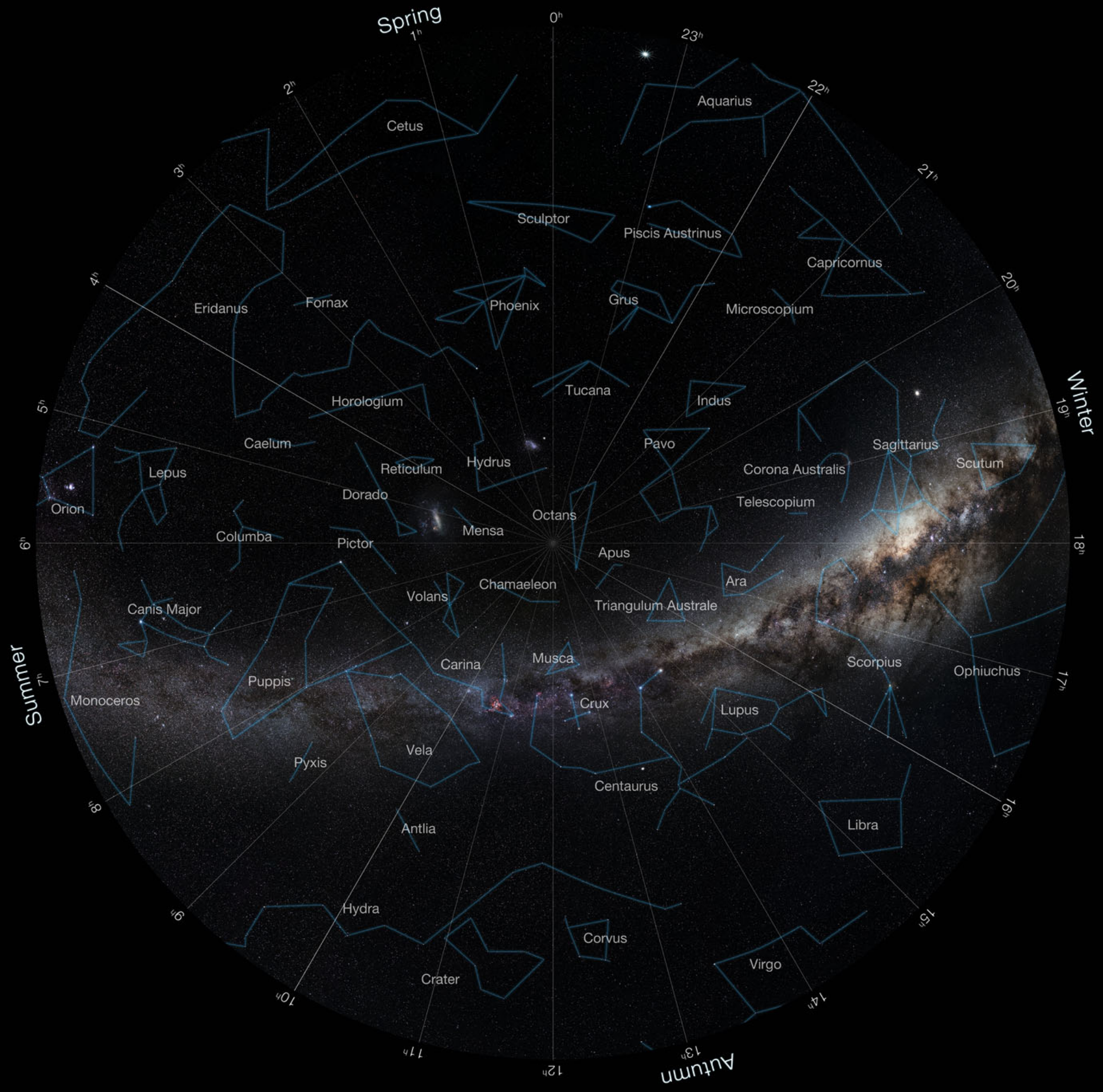

The image came about as a collaboration between the European Southern Observatory (ESO), the renowned French writer and astrophotographer Serge Brunier, and his fellow Frenchman Frédéric Tapissier. Brunier spent several weeks capturing the sky, mostly from ESO's observatories at La Silla and Paranal in Chile. On the right the southern constellations are overlaid on top of the image. Also marked are the four parts of the sky that are the most prominent in the four southern seasons: summer, fall, winter, and spring. 